muscularly in infants and young children. School age children are not sedated but I tell them in detail what is going to happen.

I have collected 178 biopsy specimens with the paediatric capsule from children with a mean age of 6.0 years (SD 5.5, range 5 months to 15 years) and 21 with the adult capsule in patients with a mean age of $16 \cdot 7$ years (SD $2 \cdot 1$, range 14-21 years). One out of 200 children (a 7 year old boy) refused to open his mouth. The table gives the results.

This rapid method is appreciated by parents and older children and by the hospital staff. In routine clinical work I have not seen any advantage in using a steerable apparatus for small bowel biopsy such as recently described.'

Department of Paediatrics,

University Central Hospital of

Tampere,

33520 Tampere 52, Finland

' Vanderhoof JA, Hunt LI, Antonson DL.. A rapid procedure for small intestinal biopsy in infants and children. (iastroenterology 1981;80:938-41.

\section{Psychogenic facial pain: presentation and treatment}

SIR,-We are carrying out work similar to that described by $\mathrm{Dr}$ Charlotte Feinmann and others (11 February, p 436) but are concentrating on those patients whose pain does not appear to fall into diagnosable categories such as temporomandibular joint dysfunction; and our patients have also proved resistant to other forms of treatment. We have been using a computer delivered self rating scale for depression, : and, as we have reported in a preliminary study, 14 out of $17\left(82^{\prime \prime}\right)$ patients assessed had abnormal depression scores. ${ }^{3}$ Of those abnormal scores, half were in the moderate and severe range.

We therefore believe that an affective disorder may play an important part in facial pain syndromes that are considered to be atypical or psychogenic. In view of these findings we are now carrying out a double blind, placebo controlled study using a nontricyclic antidepressant (mianserin (Norval)) as it might be appropriate to avoid the dry mouth that would be likely to be associated with the use of tricyclics such as dothiepin.

Department of Psychopharmacology,

R J ANCILL

Institute of Psychiatry,

London SE5 8AF

Department of Oral Surgery,

University of Glasgow,

' Carr AC, Ancill RJ, Ghosh A, Margo A. Direct assessment of depression by microcomputer: 415-22.

415-22.

of depression by Ancill RJ, Carr AC. Assessment of depression by $\mathrm{m}$

${ }^{3}$ Still DM, McGowan DA, Bond MR, Ancill RJ. A preliminary study of computer-assisted diagnosis
of depression in patients with atypical facial pain. Int $\mathcal{F}$ Oral Surg (in press)

\section{Incidence of cardiac arrhythmias in patients taking slow release salbutamol and terbutaline for asthma}

SIR,-Whether systemic beta agonists are associated with increased mortality directly related to underlying cardiac arrhythmias is a complex question and will be answered conclusively only by large multicentre studies akin to those with beta blockers.

But we are all tempted to believe that this is a fundamental truth, and subjective bias will always creep into the analysis of data from studies such as the one published by $\mathrm{Dr} \mathrm{A} \mathrm{H} \mathrm{Al-Hillawi}$ and others (4 February, p 367).

Although I have no quibble with their conclusions (my own personal bias), which no doubt stemmed from the objectives of their study - that is, that salbutamol and terbutaline are associated with an increase in resting or sleeping heart rate and an increased incidence of cardiac arrhythmiasthere is a paucity of information on which they base their conclusions. For instance, no information on the frequency and duration of these arrhythmias on either control or treatment days was included and, if the degree of airways obstruction in these patients is relevant, this was inadequately assessed. Such findings could have easily been explained by inadequate control of bronchospasm (despite "appropriate" treatment, as no drug concentrations were measured on study days and no information given on the number of aerosol inhilations taken by these patients). Furthermore, although this was a randomised study on active days, one could hardly refer to it as single blind, as control and active days were clearly distinguishable by the patients.

Also the recording of maximum heart rate for each patient is unclear and in this study ill defined. If these data had been the result of momentary activity it would indicate a physiological rather than a pharmacological phenomenon. A more meaningful way of obtaining this information might have been to calculate the average 12 hour heart rate or, more accurately, to examine a period during undisturbed sleep. This could be determined by a visual printout of the electrocardiographic $\mathbf{R}-\mathbf{R}$ intervals and by computer calculation of 15 minute average heart rates. May I suggest that the minimum average heart rates over a period of at least one hour might have produced a more conclusive result than the ones expressed here.

Another point worthy of consideration is the additional analysis of the electrocardiogram during the daytime, when sympathetic activity is normal rather than reduced. This may have shown that the arrhythmias were also present in those individuals during their waking activities on control days as a consequence of increased sympathetic tone and thus not a direct effect of the beta agonists under study.

Only five of the 16 patients studied exhibited arrhythmias as loosely defined by the authors and three of these were also seen in these subjects on control days; the data are thus inconclusive (either biologically or statistically) that either salbutamol or terbutaline caused the abnormalities described. Indeed, in the two patients showing atrial salvos or paroxysmal atrial tachycardias respectively, both common findings in normal patients and those with asthma, the peak expiratory flow measurements were either omitted or they indicated a degree of deterioration while receiving bronchodilator treatment. Most slow release preparations have notoriously variable pharmacokinetics and could fluctuate appreciably depending on the volume and type of food taken with the preparation on the evening of each study day.

I would suggest that under the circumstances a more detailed study of airway state should have been made in these patients to validate the conclusions offered.

Philip Harrison

London SE3

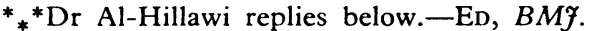

SIR,-We cannot accept all Dr Harrison's remarks but we are pleased to furnish more data on the arrhythmias encountered (table). These data were not supplied for the sake of brevity but they do not affect our argument.

We agree that it is necessary to recognise partiality, hence our tapes were read in random order by a single observer who was unaware of which drug treatment (if any) each patient had received. Furthermore, the analysis of the arrhythmias was as impartial as possible.

We agree that larger studies are required into this complex problem, in particular to see whether these arrhythmias can be attributed to drugs, hypoxia, or electrolyte disturbance. We have already started a larger, more detailed study.

\section{Middlesex Hospital,}

A H Al-Hillawi London WIN 8AA

\section{Goats' milk in infants and children}

SIR,-Folate deficiency was one of the potential hazards of infant feeding with goats' milk raised by Dr L S Taitz and Miss B L Armitage (11 February, p 428). Although megaloblastic anaemia of infancy is associated with prolonged unsupplemented feeding with either human or cows' milk it is particularly prevalent in areas where feeding with goats' milk is common, so much so that "goats' milk anaemia" is synonymous with folate deficient megaloblastic anaemia in these areas.

Infant folate requirement has been estimated at between 20 and $50 \mu \mathrm{g} /$ day (between four and ten times that of an adult weight for weight): goats' milk contains about $6.5 \mu \mathrm{g}$ of folate per litre (compared with $42 \mu \mathrm{g} / 1$ in cows' milk $^{1}{ }^{2}$ ) and is also poor in vitamin $\mathrm{B}_{12 .}{ }^{3}$ Use of unsupplemented goats' milk, therefore, results in a megaloblastic anaemia, usually at 5-9 months of age compared with at 10 months after unsupplemented cows' milk and at 2-3 months after unsupplemented evaporated milk formulas. ${ }^{3}$ Infection or diarrhoea can precipitate or aggravate the anaemia whatever the primary cause.

Although always associated with megaloblastic changes in the marrow, this anaemia is

Further details of arrhythmias observed either before or during treatment with slow release $\beta_{2}$ agonist preparations (patients as in table in our paper)

\begin{tabular}{|c|c|c|c|}
\hline \multirow[b]{2}{*}{ Case No } & \multirow{2}{*}{$\begin{array}{l}\text { Baseline readings } \\
\text { (beats } / \mathrm{min})\end{array}$} & \multicolumn{2}{|c|}{ Readings on seventh day of treatment } \\
\hline & & Terbutaline (beats/min) & Salbutamol (beats/min) \\
\hline 1 (age 27) & & $\begin{array}{l}\text { Bifocal ventricular premature beat(s) } \\
(0 \text { to } 18)\end{array}$ & $\begin{array}{l}\text { Single ventricular premature beat } \\
(0-1)\end{array}$ \\
\hline 2 (age 42) & $\begin{array}{l}\text { Single ventricular } \\
\text { premature beat }(0-1)\end{array}$ & $\begin{array}{l}\text { Single and paired ventricular } \\
\text { premature beat }(s)(0-12)\end{array}$ & $\begin{array}{l}\text { Single ventricular premature beat } \\
(0-1)\end{array}$ \\
\hline 3 (age 60) & & $\begin{array}{l}\text { Frequent bifocal ventricular } \\
\text { premature beat }(s)(2-15)\end{array}$ & $\begin{array}{l}\text { Unifocal ventricular premature } \\
\text { beat }(\mathrm{s})(0-12)\end{array}$ \\
\hline 4 (age 31 ) & Atrial extrasystoles $(0-1)$ & & $\begin{array}{l}\text { Salvos of paroxysmal atrial } \\
\text { tachycardia (maximum } \\
\text { duration } 2 \cdot 4 \mathrm{~s}, 0-6 \text { salvos/hour) }\end{array}$ \\
\hline 5 (age 60) & Atrial extrasystoles $(0-4)$ & & $\begin{array}{l}\text { Paroxysmal atrial tachycardia } \\
\text { (164 seconds' duration } \\
\text { maximum rate } 148 / \mathrm{min} \text { ) }\end{array}$ \\
\hline
\end{tabular}

